\title{
Endocrine Disrupting Chemicals and Premenstrual Syndrome in Female College Students in East Asia: A Multi-Country Study
}

\author{
Jeongok Park $\mathbb{D}^{\prime}$, Jung Jae Lee $\mathbb{D}^{2}$, SoMi Park $\mathbb{D}^{3}$, Hyeonkyeong Lee $\mathbb{D}^{\prime}$, Sujin Nam $\mathbb{D}^{2}$, Sejeong Lee $\mathbb{D}^{4}$, \\ Hyojin Lee $\mathbb{B}^{4}$ \\ 'College of Nursing, Mo-Im Kim Nursing Research Institute, Yonsei University, Seoul, Korea; ${ }^{2}$ School of Nursing, Li Ka Shing Faculty of Medicine, \\ University of Hong Kong, Hong Kong, People's Republic of China; ${ }^{3}$ Department of Nursing, Wonju College of Medicine, Yonsei University, Wonju, \\ Korea; ${ }^{4}$ College of Nursing and Brain Korea 2I FOUR Project, Yonsei University, Seoul, Korea \\ Correspondence: Hyojin Lee, College of Nursing and Brain Korea 2I FOUR Project, 50-I, Yonsei-Ro, Seodaemun-gu, Seoul, 03722, Korea, \\ Tel +82-10-4756-0692, Email 92Ihlee@gmail.com
}

\begin{abstract}
Purpose: This study aimed to explore the severity of premenstrual syndrome (PMS) and to examine associated factors with PMS among East Asian female college students with regard to endocrine-disrupting chemical (EDC).

Patients and Methods: This study was a cross-sectional design. An online survey was completed by 520 female college students in Hong Kong and Korea. The structured questionnaire included items measuring knowledge of EDCs, actions taken and willingness to minimize exposure to EDCs, interest in EDCs, prior education on EDCs, life stress, severity of PMS, and general and health-related characteristics. Multiple logistic regressions were performed.

Results: The prevalence of severe PMS among the participants was 54.6\%. Factors associated with severe PMS included a selfreported heavy menstrual flow, underweight, obesity, interpersonal relationship stress, actions taken to minimize exposure to EDCs, and interest in EDCs.

Conclusion: This study provided the evidence of a negative association between severe PMS and the actions taken to minimize exposure to EDCs. To alleviate symptoms of PMS among young female adults, practical interventions, such as education to overcome barriers to preventing exposure to EDCs, are suggested.
\end{abstract}

Keywords: women's health, public health nursing, reproductive health

\section{Introduction}

Many items used for everyday activities contain endocrine-disrupting chemicals (EDCs), or environmental hormones, which are defined as exogenous chemicals, or mixtures of chemicals, that interfere with any aspect of hormone action. ${ }^{1}$ EDCs such as Bisphenol-A (BPA), phthalates and parabens are found in many daily items including food and drinking packaging, cosmetics, and personal care products. ${ }^{2}$ Increased exposure to EDCs has become a global health concern as it can cause negative health outcomes. EDCs are known to contribute to physical and psychological health problems including diabetes, obesity, ${ }^{2}$ anxiety, and aggression. ${ }^{3}$ Young women in both Hong Kong and South Korea (hereafter Korea) are heavily exposed to EDCs due to frequent uses of plastic products from their westernized lifestyle, which involves beauty product use and altered dietary habits. ${ }^{4-7}$

The high level of exposure to EDCs may cause increased EDC-associated health risk in young women, including premenstrual syndrome (PMS). PMS refers to a group of symptoms of discomfort caused by the action of the endocrine system occurring in advance to menstrual period. ${ }^{8}$ Women with severe PMS have been reported to have worsened quality of life and socio-occupational functioning. ${ }^{8}$

Considering the connections between EDCs and PMS from previous literature, ${ }^{9}$ young people in Hong Kong and Korea are at risk of harmful consequences of exposure to EDCs. Existing studies ${ }^{4,5}$ have shown that young women in 
both countries use a large quantity of cosmetic products, a major source of exposure to phthalates, paraben, and BPA. ${ }^{2,10}$ In addition, fast food and convenience food have become an integral part of young people's eating habits due to price, convenience, and the influence of western culture. ${ }^{6,7} \mathrm{~A}$ report also revealed that Hong Kong and Korea produced a significant quantity of plastic waste in 2010. The countries produced approximately 1 and 2 million tons of plastic waste, and were ranked 45th and 29th among 169 countries, respectively. ${ }^{11}$ The report also indicated that, in 2015 , each individual generated $0.40 \mathrm{~kg}$, which was the greatest quantity, and $0.11 \mathrm{~kg}$ plastic waste per day in Hong Kong and Korea, respectively. Additionally, it is likely that the exposure levels to EDCs will significantly increase during COVID-19 pandemic since more plastic products such as plastic food containers for take-out services have been used. ${ }^{12}$

The high level of exposure to EDCs is associated with high health risk in young women, and may affect reproductive health by increasing the risk of breast, uterine, ovarian, and cervical cancers. ${ }^{1,2}$ EDCs may also affect the risk of endometriosis and infertility, which is supported by empirical evidence found in the literature on heavy metals, such as Cadmium and lead and their endocrine-disrupting effects on women's health. High levels of Cadmium were found in women with endometriosis. ${ }^{13}$ In another study, the levels of lead in patients with endometriosis and ongoing pregnancies were lower than those in non-pregnant patients, implying the negative influence of lead on fertility. ${ }^{14}$ In women of childbearing age, EDC exposure during fetal or neonatal periods may affect the brain and behavior of offspring. ${ }^{3}$ This also implies that EDCs may be delivered from one generation to another, making them potentially hazardous matters for the health of the next generation of human beings. In this context, PMS is also known to be affected by exposure to EDCs and, moreover, a prior study identified EDC exposure as the most powerful predictor for PMS. ${ }^{9}$

PMS refers to a broad group of emotional, behavioral, and physical symptoms occurring for several days to several weeks before menstruation and subsiding after the menstrual period, including breast tenderness, abdominal swelling, fatigue, sleep disorders, irritation, and mood swings. ${ }^{15}$ It is known that PMS affects all aspects of one's quality of life, including physical, mental, and social domains. ${ }^{16}$ The reported prevalence of PMS varies between studies. Previous reports have shown that $76 \%$ to $99 \%{ }^{15,17}$ of young fertile women in Hong Kong and Korea have been reported to experience at least one symptom of PMS.

Although a comprehensive evaluation of knowledge, behaviors, interest, engagement, and education on EDCs is needed to minimize negative impacts of EDC exposure, little research has been conducted for young women in East Asia. An in-depth understanding of the status of young adult women regarding EDCs will facilitate the identification of individual needs and development of appropriate interventions designed to reduce EDC exposure levels, which would reduce PMS in young women. The conceptual framework of this study was developed based on the Theory of Unpleasant Symptoms (TOUS) published by Lenz et al. ${ }^{18}$ The TOUS considers symptom experiences as a multi-dimensional concept and proposes that symptoms are affected by physiological, psychological, and situational factors. Based on the TOUS, this study aimed to examine the association between EDCs and PMS in young women in Hong Kong and Korea (Figure 1).

The specific aims are the followings:

1. To explore the prevalence and severity of PMS among the East Asian female college students.

2. To investigate the difference in the severity of PMS according to physiological, psychological and situational factors, and characteristics of the East Asian female college students.

3. To examine factors associated with PMS of the East Asian female college students.

\section{Materials and Methods}

\section{Design and Participants}

This study employed a cross-sectional, web-based design to identify factors associated with PMS. Research project titled "East Asian female college students' health status and health behaviors" was conducted in Korea and Hong Kong. Participants were female college students living in Korea and Hong Kong, who understood the purpose of the study and voluntarily agreed on their participation. Those who had access to the internet through computer or smartphone to 


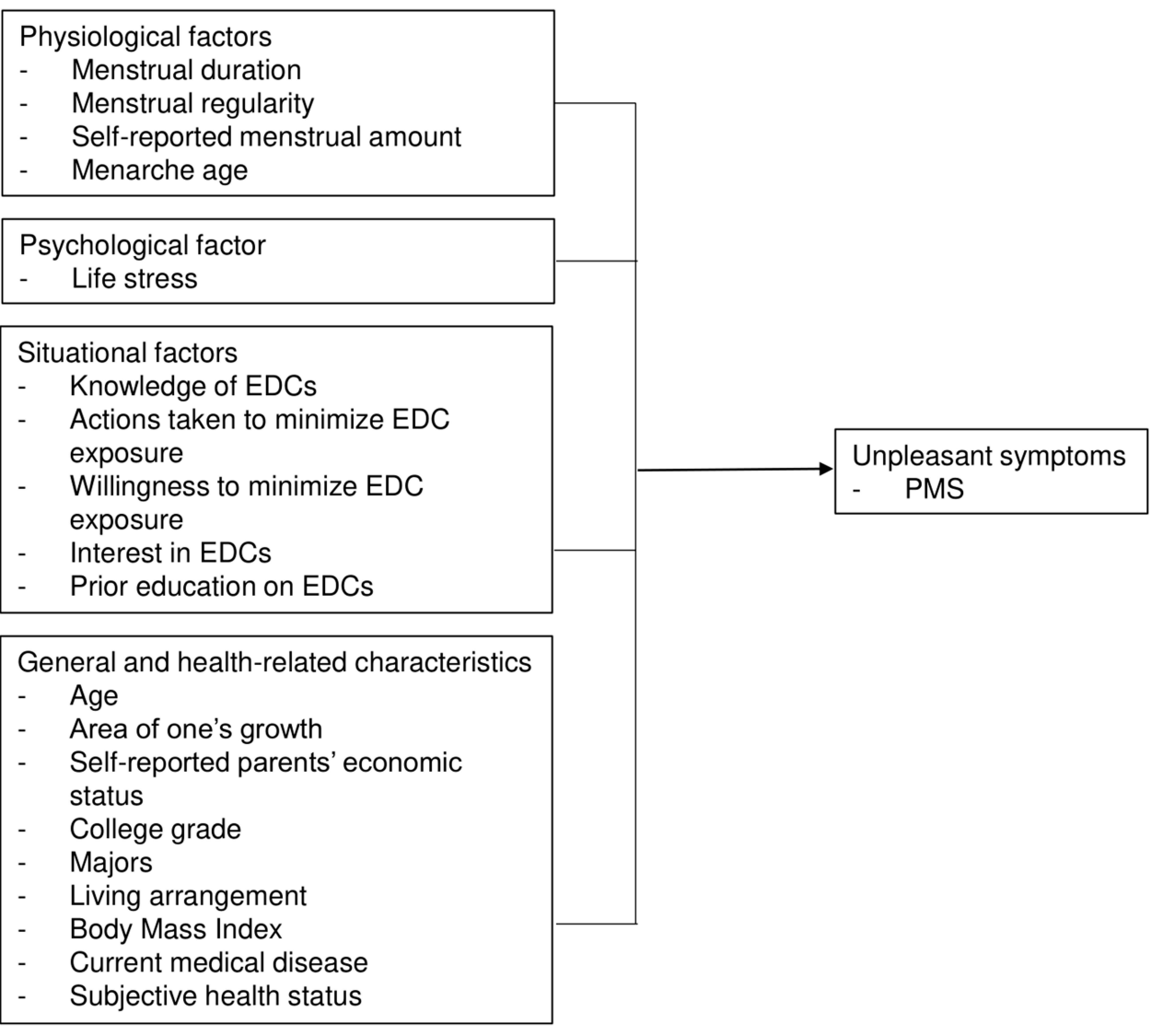

Figure I Conceptual framework of the study based on the theory of unpleasant symptom. Abbreviations: EDCs, endocrine disrupting chemicals; PMS, premenstrual syndrome.

participate online survey were included in this study, while those with previous or current pregnancy, or a history of psychological disorders such as depression or anxiety disorders diagnosed by a medical doctor were excluded.

\section{Data Collection}

An online survey using a structured questionnaire was conducted from June to October 2019. In Hong Kong, a public university in which one of the authors was affiliated with was targeted for recruitment. Mass recruitment emails, which included the online survey link, were sent to all female students at the university. In Korea, participants were recruited from websites that are frequently visited by college students. Institutional Review Board (IRB) in both countries approved conducting the study, and all the study processes were performed in accordance with relevant regulations. Informed consent was obtained online from all participants. At the beginning of the web page of the survey, the purpose of the study, study period, inclusion criteria for participation, study methods, expected effects and risks to participants, confidentiality, anonymity, and freedom with withdrawal were explained in detail. It was considered as a voluntary agreement for participation when participants checked on the checkbox of agreement and clicked the start button for survey.

\section{Measures}

EDCs-related instruments and questions originally developed in Korean, including those for assessing knowledge of EDCs, action taken and willingness to minimize exposure to EDCs, interests in EDCs, prior education on EDCs, and life stress, were translated into English for participants in Hong Kong (n.b., tertiary education is delivered in English in Hong Kong). Materials were first translated into English and then back-translated to ensure accuracy and to retain the original meaning. Translations and back-translations were performed by two bilingual translators. The Shortened 
Premenstrual Assessment Form (SPAF), assessing PMS, was originally developed in English. The original version was used for participants in Hong Kong, and a translated Korean version was used for participants in Korea.

Knowledge of EDCs was assessed using a 25 -item questionnaire developed by Kim and Kim. ${ }^{19}$ Participants were asked to respond to each item with certain statements about EDCs, using "true", "false", and "don't know"; incorrect and "don't know" were scored as 0 , and correct responses received a score of 4 . The total possible score range was 0-100, whereby higher scores indicated a greater knowledge of EDCs. The Cronbach's $\alpha$ was 0.74 in the instrument development study, and 0.87 in this study.

Actions taken to minimize EDC exposure were assessed using a questionnaire developed by Kim and Kim, ${ }^{19}$ and modified by Chung et al. ${ }^{20}$ The modified version includes 24 items scored on a 4-point Likert scale, and the possible score range was $0-96$, whereby higher scores indicated a more frequent engagement in activities to minimize EDC exposure. The Cronbach's $\alpha$ was 0.83 in the instrument development study, and 0.74 in this study.

Willingness to minimize EDC exposure was measured using a single item, "Put a check mark next to the statement that represents your opinion", which was followed by the five following statements: 1) "I have consistently tried and will continuously try to minimize exposure to EDCs"; 2) "I have occasionally tried to minimize exposure to EDCs, but will continuously try from now on"; 3) "I have never tried to minimize exposure to EDCs, but will do so in the near future"; 4) "I have never tried to minimize exposure to EDCs, but I am thinking about doing so occasionally"; and 5) "I have never and will never try to minimize exposure to EDCs". The possible score range was from 1 to 5 , with higher scores indicating a greater willingness to minimize EDC exposure.

Interest in EDCs was measured using a single question, "How interested are you in EDCs?", which was rated on a scale from 0 to 10. Higher scores indicated a greater interest in EDCs.

Prior education on EDCs was measured using a single question, "Have you ever been taught about EDCs?". It was required to be answered among "Yes" or "No".

Life stress was measured using a 50-item questionnaire developed by Chon et al. ${ }^{21}$ The questionnaire measures two subcategories - task-related stress and interpersonal relationship stress. Task-related stress (27 items) measured the frequencies and importance of life stress about academic performance, economic issues, issues about the future, and issues about value. Interpersonal relationship stress (23 items) measured the frequencies and importance of life stress in relationships with a lover, friends, family, and professors. Each item was scored on a 4-point Likert scale, and the possible score range was 0150, whereby higher scores indicated more frequent experiences of life stress events. The instrument measured both frequency and importance of the life events, although those who reported a frequency of " 0 " were not required to answer the important question. Consequently, only frequency data were included in the final analysis. The Cronbach's $\alpha$ was $0.75-$ 0.88 in each sub-category in the instrument development study, and 0.93 in this study.

The SPAF was developed by Allen et $\mathrm{al}^{22}$ and modified and translated into Korean by Lee et $\mathrm{al}^{23}$ The SPAF comprises 10 items, each measuring changes in emotion, pain, and water retention in the week prior to menstruation on a 6-point Likert scale. The possible score range is 10-60, whereby higher scores indicate a greater PMS severity. The cutoff score for premenstrual dysphoric syndrome (PMDD), a severe form of PMS, was 27. Cronbach's $\alpha$ was 0.91 in the translation study, and 0.90 in this study.

Data on age, area where participants grew up, parents' economic status, college grade, majors, living arrangement, body mass index (BMI), past and current medical history, subjective health status, menarche age, and menstrual duration, regularity and amount were collected.

\section{Statistical Analysis}

The data were analyzed using SPSS version 25.0. Demographic characteristics and the main variables were analyzed using descriptive statistics, including mean, standard deviation (SD), and percentage (\%). An independent $t$-test and oneway analysis of variance (ANOVA) were used to perform univariate analyses of the main variables according to PMS severity. To identify the factors associated with PMS, multiple logistic regressions were performed. 


\section{Results}

\section{Characteristics and Results of the Main Variables of Participants}

Participants were 520 female college students from Hong Kong $(n=300)$ and Korea $(n=220)$, with a mean age of 20.75 \pm 1.77 years. More than half were living with their parents $(56.3 \%)$. BMI was normal in most participants $(61.7 \%)$. The majority of participants had no medical history $(86.2 \%)$ or current disease $(90.4 \%)$. The average duration of menstruation was $5.69 \pm 1.18$ days. More than a half of the participants reported that their menstruation was irregular $(60.4 \%)$. Approximately, $65 \%$ of the participants reported a moderate amount of menstruation. The average age of menarche was $12.57 \pm 1.83$ years. The average task-related stress score from the questionnaire was $27.55 \pm 13.90$ out of 81 , and the average interpersonal relationship stress score was $10.64 \pm 8.73$ out of 69 . Knowledge of EDCs and actions taken to minimize EDC exposure averaged at $52.64 \pm 23.55$ out of 100 and $66.89 \pm 7.78$ out of 96 , respectively. The average willingness to minimize EDC exposure score was $3.20 \pm 1.00$ out of 5. Most participants had received no education about EDCs (89.2\%). The average PMS score was $28.41 \pm 10.13$ out of 60 , and around $55 \%$ of participants were considered to have severe PMS.

\section{Differences in Participants' Characteristics by Premenstrual Syndrome}

Table 1 presents the results of differences in participants' characteristics between severe PMS and non-PMS groups. BMI $\left(\chi^{2}=10.499, \mathrm{p}=0.015\right)$, menstrual regularity $\left(\chi^{2}=4.295, \mathrm{p}=0.038\right)$, self-reported menstrual amount $\left(\chi^{2}=8.578, \mathrm{p}=\right.$ $0.014)$, task-related stress $(\mathrm{t}=5.650, \mathrm{p}<0.001)$, interpersonal relationship stress $(\mathrm{t}=-6.757, \mathrm{p}<0.001)$, knowledge of EDCs $(\mathrm{t}=-2.248, \mathrm{p}=0.025)$, actions to minimize EDC exposure $(\mathrm{t}=4.538, \mathrm{p}<0.001)$, and interest in EDCs $(\mathrm{t}=3.833$, $\mathrm{p}<0.001)$ were significantly different between the groups of severe PMS and non-severe PMS (Table 1.)

\section{Factors Associated with Severe Premenstrual Syndrome in Hong Kong and Korea}

The multiple logistic regression identified the followings as factors associated with PMS: self-reported menstrual amount (heavy) (odds ratio $[\mathrm{OR}]=1.72 ; 95 \%$ confidence interval $[\mathrm{CI}]=1.09-2.71)$, $\mathrm{BMI}$ underweight $(\mathrm{OR}=0.61 ; 95 \% \mathrm{CI}=$ $0.38-0.98)$, BMI obese $(\mathrm{OR}=0.37 ; 95 \% \mathrm{CI}=0.18-0.76)$, interpersonal relationship stress $(\mathrm{OR}=1.06 ; 95 \% \mathrm{CI}=1.03-$ $1.09)$, actions taken to minimize EDC exposure $(\mathrm{OR}=0.97 ; 95 \% \mathrm{CI}=0.94-0.99)$, and interest in $\mathrm{EDCs}(\mathrm{OR}=1.12 ; 95 \%$ $\mathrm{CI}=1.03-1.21)$ in the participants (Table 2).

In a sub-group analysis with Hong Kong participants, interpersonal relationship stress $(\mathrm{OR}=1.04 ; 95 \% \mathrm{CI}=1.00$ $1.09)$ and interest in EDCs $(\mathrm{OR}=1.11 ; 95 \% \mathrm{CI}=1.00-1.22)$ were significantly associated with severe PMS. Within the Korean participants, self-reported menstrual amount (heavy) $(\mathrm{OR}=2.06 ; 95 \% \mathrm{CI}=1.01-4.19)$, BMI obese $(\mathrm{OR}=0.34$; $95 \% \mathrm{CI}=0.12-0.92)$, interpersonal relationship stress $(\mathrm{OR}=1.08 ; 95 \% \mathrm{CI}=1.03-1.14)$, knowledge of EDCs $(\mathrm{OR}=$ $1.03 ; 95 \% \mathrm{CI}=1.01-1.05)$, and actions taken to minimize EDC exposure $(\mathrm{OR}=0.96 ; 95 \% \mathrm{CI}=0.92-0.99)$ were associated with severe PMS (Table 2).

\section{Discussion}

This descriptive study investigated the severity of PMS and identified factors associated with severe PMS in East Asian female college students using the TOUS conceptual framework. One of the most striking findings was that participants with high levels of knowledge and interest in EDCs were more likely to have severe PMS than those with lower levels of interest and knowledge, whereas those participating in frequent activities to minimize EDC exposure were less likely to have severe PMS than those who participated in fewer activities. This would indicate that individuals with severe PMS are more interested in EDCs, and thus, seek to acquire more information on EDCs; however, knowledge and/or interest are not sufficient to reduce the likelihood of experiencing severe PMS. Rather, taking action to reduce EDC exposure was more effective.

Strategies for reducing EDC exposure may be considered from individual, community, and government aspects. Practical interventions to reduce EDC exposure levels are needed for individuals. Previous studies based on the Health Belief Model (HBM), a widely used model for describing health practices, revealed overcoming barriers is most important maintaining continuous preventive measures and promoting behavior of college students. ${ }^{24}$ Young women 
Table I Results of Severity of Premenstrual Syndrome by Participants' Characteristics and Main Variables $(n=520)$

\begin{tabular}{|c|c|c|c|}
\hline \multirow[t]{2}{*}{ Variable } & \multicolumn{2}{|c|}{$\begin{array}{c}\text { PMS } \\
\text { Mean } \pm \text { SD (Range) or N (\%) }\end{array}$} & \multirow[t]{2}{*}{$t / X^{2}(p)$} \\
\hline & Severe PMS & No Severe-PMS & \\
\hline \multicolumn{4}{|l|}{ Characteristics } \\
\hline Nationality & & & $0.108(0.742)$ \\
\hline Korea & $122(43.0)$ & $98(4 I .5)$ & \\
\hline Hong Kong & $162(57.0)$ & $138(58.5)$ & \\
\hline Age (years) & $20.86 \pm 1.84$ & $20.61 \pm 1.68$ & $-1.620(0.106)$ \\
\hline Area of one's growth & & & $1.119(0.572)$ \\
\hline Metropolitan area & $153(53.9)$ & I $37(58.1)$ & \\
\hline City & III (39.I) & $86(36.4)$ & \\
\hline Rural area & $20(7.0)$ & $13(5.5)$ & \\
\hline Self-reported parents' economic status & & & $2.757(0.252)$ \\
\hline Upper & $20(7.0)$ & $13(5.5)$ & \\
\hline Middle & $205(72.2)$ & $160(67.8)$ & \\
\hline Lower & $59(20.8)$ & $63(26.7)$ & \\
\hline College grade & & & $1.795(0.616)$ \\
\hline Year I & $44(15.5)$ & $44(18.6)$ & \\
\hline Year 2 & $77(27.1)$ & $63(26.7)$ & \\
\hline Year 3 & $62(21.8)$ & $56(23.7)$ & \\
\hline Year 4 or higher & $101(35.6)$ & $73(31.0)$ & \\
\hline Majors & & & $3.242(0.5 \mid 8)$ \\
\hline Humanities, social sciences & II4 (40.I) & $97(4 I .1)$ & \\
\hline Natural sciences, engineering & $57(20.1)$ & $49(20.8)$ & \\
\hline Health & $79(27.8)$ & $60(25.4)$ & \\
\hline Arts, sports & $26(9.2)$ & $17(7.2)$ & \\
\hline Others & $8(2.8)$ & $13(5.5)$ & \\
\hline Living arrangement & & & $1.216(0.758)^{\mathrm{a}}$ \\
\hline Live alone & $25(8.8)$ & $18(7.6)$ & \\
\hline Live with parents & $159(56.0)$ & $134(56.8)$ & \\
\hline Live in dormitory or with friends & $93(32.7)$ & $81(34.3)$ & \\
\hline Others & $7(2.5)$ & $3(1.3)$ & \\
\hline Body Mass Index & & & $10.499(0.015)$ \\
\hline <18.5 (underweight) & $49(17.3)$ & $58(24.6)$ & \\
\hline I8.5-22.9 (normal) & $187(65.8)$ & I34 (56.8) & \\
\hline 23.0-24.9 (overweight) & $31(10.9)$ & $18(7.6)$ & \\
\hline$\geq 25$ (obese) & $17(6.0)$ & $26(11.0)$ & \\
\hline Past medical history & & & $0.183(0.669)$ \\
\hline Yes & $41(14.4)$ & $31(11.1)$ & \\
\hline No & $243(85.6)$ & 205 (88.9) & \\
\hline Current medical disease & & & $0.153(0.696)$ \\
\hline Yes & $26(9.2)$ & $24(10.2)$ & \\
\hline No & $258(90.8)$ & $212(89.9)$ & \\
\hline Subjective health status & $5.60 \pm 1.87$ & $5.83 \pm 1.82$ & $1.404(0.161)$ \\
\hline
\end{tabular}

(Continued) 
Table I (Continued).

\begin{tabular}{|c|c|c|c|}
\hline \multirow[t]{2}{*}{ Variable } & \multicolumn{2}{|c|}{$\begin{array}{c}\text { PMS } \\
\text { Mean } \pm \text { SD (Range) or N (\%) }\end{array}$} & \multirow[t]{2}{*}{$t / X^{2}(p)$} \\
\hline & Severe PMS & No Severe-PMS & \\
\hline \multicolumn{4}{|l|}{ Main variables } \\
\hline \multicolumn{4}{|l|}{ Physiological factors } \\
\hline Menstrual duration (days) & & & I.109 (0.292) \\
\hline Normal ( $\leq 8$ days) & $282(99.3)$ & $232(98.3)$ & \\
\hline Prolonged (>8 days) & $2(0.7)$ & $4(1.7)$ & \\
\hline Menstrual regularity & & & $4.295(0.038)$ \\
\hline Regular & $101(35.6)$ & $105(44.5)$ & \\
\hline Irregular & $183(64.4)$ & $|3|(55.5)$ & \\
\hline Self-reported menstrual amount & & & $8.578(0.014)$ \\
\hline Light & $29(10.2)$ & $26(11.0)$ & \\
\hline Moderate & $172(60.6)$ & $167(70.8)$ & \\
\hline Heavy & $83(29.2)$ & $43(18.2)$ & \\
\hline Menarche age (years) & $12.54 \pm 1.68(8-2 \mid)$ & $12.60 \pm 1.99(7-24)$ & $0.415(0.678)$ \\
\hline \multicolumn{4}{|l|}{ Psychological factors } \\
\hline \multicolumn{4}{|l|}{ Life stress } \\
\hline Task-related stress (score range: $0-8 \mathrm{I}$ ) & $30.60 \pm 13.97(3-76)$ & $23.88 \pm|2.9|(0-58)$ & $5.650(<.001)$ \\
\hline Interpersonal relationship stress (score range: 0-69) & $12.85 \pm 9.46(0-45)$ & $7.99 \pm 6.90(0-45)$ & $-6.757(<.001)$ \\
\hline \multicolumn{4}{|l|}{ Situational factors } \\
\hline Knowledge of EDCs (score range: $0-100$ ) & $54.75 \pm 23.29(0-92)$ & $50.10 \pm 23.67(0-100)$ & $-2.248(0.025)$ \\
\hline Actions taken to minimize EDC exposure (score range: $0-100$ ) & $65.52 \pm 8.03(44-87)$ & $68.54 \pm 7.12(47-87)$ & $4.538(<.001)$ \\
\hline Willingness to minimized EDC exposure (score range: $1-5$ ) & $3.27 \pm 0.94(I-5)$ & $3.1 I \pm 1.07(I-5)$ & $-1.825(0.069)$ \\
\hline Interest in EDCs (score range: $0-10$ ) & $5.27 \pm 2.38(0-10)$ & $4.47 \pm 2.33(0-10)$ & $3.833(<.001)$ \\
\hline Prior education on EDCs & & & $0.014(0.906)$ \\
\hline Yes & $31(10.9)$ & $25(10.6)$ & \\
\hline No & $253(89.1)$ & $211(89.4)$ & \\
\hline
\end{tabular}

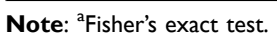

Abbreviations: EDCs, endocrine disrupting chemicals; PMS, premenstrual syndrome.

benefit from knowledge of specific ways in which EDC exposure levels may be reduced in everyday life such as altering dietary habits, using BPA-free cosmetics and food containers, and avoiding microwaving cup-noodles. An experimental study revealed that dietary modification was effective for reducing urinary EDC levels and alleviating menstrual pain. ${ }^{25}$ Detailed information on EDCs and diet can encourage young women to perform self-protective actions and change their behaviors regarding usage of EDC sources in everyday life. ${ }^{25}$

In community, nurses in schools and colleges should offer access to a diverse set of information on PMS, including the effects of EDCs. Since unmarried women visiting obstetrics and gynecology clinics in Asian countries are perceived unfavorably, voluntarily visiting such health care centers for PMS symptoms occurs rarely. ${ }^{26}$ This makes the role of school nurses more important.

The role of government involves the regulation of industry. Tests evaluating the effects of chemicals used in industrial products on the endocrine system require improvements, including increasing numbers of chemicals tested. Only the 
Table 2 Results of Multiple Logistic Regressions of Factors Associated with Severe Premenstrual Syndrome in Korea and Hong Kong $(n=520)$

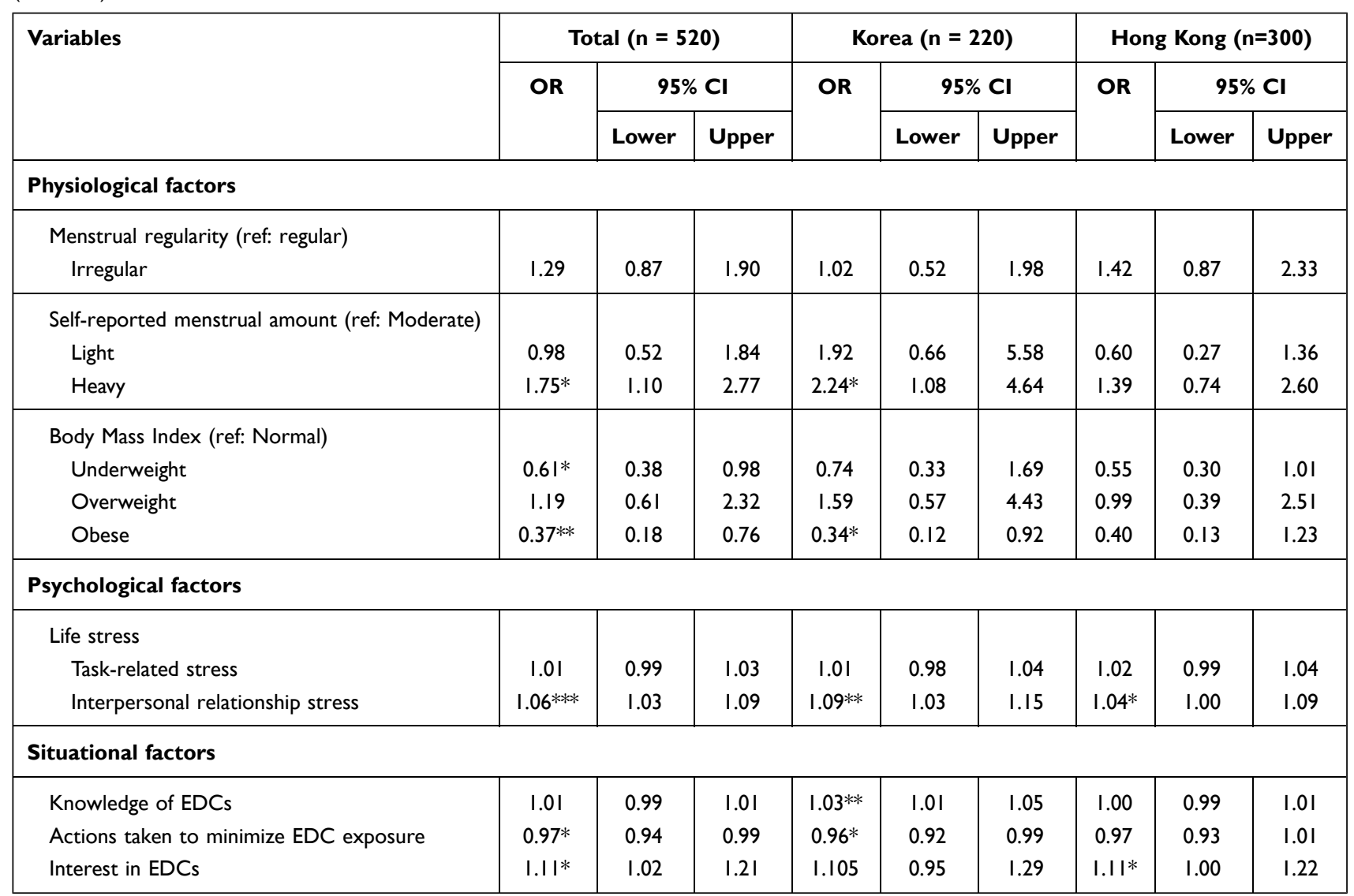

Notes: ${ }^{*} \mathrm{p}<0.05, * *_{\mathrm{p}}<0.01,{ }^{*} * \mathrm{p}<0.001$.

Abbreviation: EDCs, endocrine disrupting chemicals.

effects of some chemicals on the endocrine system have been tested. ${ }^{10}$ Effective protection from EDCs will be possible when protective measures are based on accurate information regarding EDC sources and dynamics. It is also necessary to strengthen the labeling of EDCs. Insufficiency in labeling of EDC content within industrial products has been suggested. ${ }^{27}$ In the US, the Consumer Product Safety Improvement Act (CPSIA) states that traceable information on children's products should be marked on products and packaging, and the labeling of food containers containing BPA was enforced by Prop. 65 in California. ${ }^{28}$ Meanwhile, policies in Hong Kong and Korea remain in rudimentary stages. Hong Kong does not yet have specialized EDC regulations. ${ }^{29}$ Separate laws for regulating EDCs in Korea also lack, and many laws regulate EDCs in the same manner as other chemicals. ${ }^{30}$ There are various types of EDCs and pathways of exposure, making it difficult to specify each and every EDC. However, strengthening and standardizing the labeling of EDCs still remains important.

The results from the current study and previous literature suggest that young adults in industrialized countries with high risk of EDC exposure be encouraged to develop behaviors that will reduce EDC exposure levels via interventions on individuals, community, and government. This is especially critical considering that lifestyle habits during young adulthood continue to affect health throughout subsequent periods of adult. ${ }^{31}$ Practical strategies beyond the simple transfer of knowledge are required for individuals to actually bring out changes in behaviors. School nurses' roles should include a systematic screening and proper care of severe PMS, and referrals if needed. The government has called for the creation of stricter regulations for manufacturing industrial products.

Regarding the severity of PMS of the participants, mean SPAF score was $28.41 \pm 10.13$. This is similar to previous

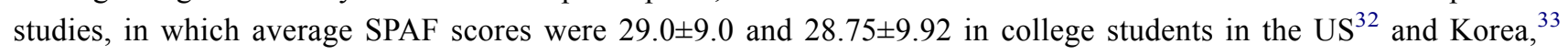


respectively. Severe PMS, defined as an SPAF score $\geq 27$, occurred $54.6 \%$ of all study participants. In previous work, $36.3 \%$ of Korean high-school freshmen ${ }^{34}$ were categorized as having severe PMS. The elevated prevalence of severe PMS in the current study versus the study that included Korean high-school students might be a result of the living arrangements of participants. In the present study, $43.7 \%$ of the participants did not live with their parents. Living away from parents likely increases exposure to environmental hormones due to unhealthy eating habits. ${ }^{35}$

We found that stress and severe PMS were significantly associated, which is consistent with previous studies. Abnormalities in stress reactivity, individual vulnerability to stress, and consumption of an imbalanced diet due to stress may contribute to PMS. In one Chinese study, those with PMS possessed abnormal emotional state and stress reactivity, with pronounced electroencephalogram alpha activity and low respiration rates. ${ }^{36}$ A study of Korean college students found that impact/event ratio scores during the premenstrual phase were higher in women with PMS than in those without, indicating that women with more severe PMS were more vulnerable to stressful events. ${ }^{37}$ Furthermore, greater stress levels might result in worsened dietary habits. A meta-analysis found that perceived stress was associated with unhealthy dietary patterns including consumption of high-fat diets, eating sweets, and increasing salt intake in women of reproductive ages. ${ }^{38}$ An imbalanced diet causes changes in homeostasis via calcium and vitamin D, which may lead to PMS. ${ }^{39}$

Stress, and particularly interpersonal relationship stress, was significantly associated with severe PMS in this study. Previous studies have considered social relationship stress in terms of social support and social functioning, which could help to further characterize its relationship with PMS. One study reported that women with PMS have less emotional social support, meaning how much they can trust and lean on another person, and practical social support, meaning how much practical help and social time they spend with another person, than women without PMS. ${ }^{40} \mathrm{PMS}$ is also known to affect social functioning by discouraging participation in social interactions. A study of adult women in the UK revealed that women with PMDD were unable to interact socially due to frequent feelings of discomfort, sensitivity, and annoyance, which could be interpreted as affective symptoms of PMS. ${ }^{41}$

The association between BMI and PMS is inconsistent with previous reports. It is widely known that obesity is a risk factor for PMS; ${ }^{42}$ however, we found that participants with a normal BMI were more likely to have severe PMS than obese ones. The low number of overweight and obese participants in this study could potentially explain this result, and further studies should be performed to better explore the relationship between BMI and PMS in young Asian adults.

This study has several limitations. The cross-sectional design of this study makes inferring a causal relationship difficult. The present findings are also prone to selection bias due to the use of a convenience sampling method, limiting the generalizability of findings. Finally, we did not directly measure levels of EDC exposure using biomarkers, such as urinary EDC concentration. Thus, further longitudinal studies are needed to validate our results. Future work to determine the effect of EDCs in women with severe PMS is suggested, since these are the women who most need medical interventions. Finally, studies considering both situational factors influencing EDC exposure and indicators of actual EDC exposure may further expand on the present results.

\section{Conclusion}

This study examined the severity and prevalence of PMS in Hong Kong and Korean female college students and identified factors significantly associated with PMS. A significant relationship between stress and PMS was identified, and the importance of taking actions to avoid EDC exposure was revealed, which has meaningful implications with regard to nursing practices and health education.

\section{Ethical Consideration and Consent to Participate}

This study was approved by the IRB of the University of Hong Kong (UW19-484) before data collection started. Research ethics approval was also obtained from IRB in Korea by Yonsei University (Y-2019-0055). This study complies with the Declaration of Helsinki.

\section{Author Contributions}

All authors made a significant contribution to the work reported, whether that is in the conception, study design, execution, acquisition of data, analysis, and interpretation, or in all these areas; took part in drafting, revising or critically 
reviewing the article; gave final approval of the version to be published; have agreed on the journal to which the article has been submitted; and agree to be accountable for all aspects of the work.

\section{Funding}

This study was supported by the 2018 International Joint Research Grant from Mo-Im Kim Nursing Research Institute (6-2018-0120), and the Brain Korea 21 FOUR Project funded by National Research Foundation (NRF) of Korea, Yonsei University College of Nursing (F21JB7504007).

\section{Disclosure}

The authors declare they have no actual or potentially competing financial interests.

\section{References}

1. Zoeller RT, Brown TR, Doan LL, et al. Endocrine-disrupting chemicals and public health protection: a statement of principles from the Endocrine Society. Endocrinology. 2012;153(9):4097-4110. doi:10.1210/en.2012-1422

2. World Health Organization. State of the science of endocrine disrupting chemicals 2012: summary for decision-makers; 2012. Available from: www.who.int. Accessed January 24, 2022.

3. Braun JM, Kalkbrenner AE, Calafat AM, et al. Impact of early-life bisphenol A exposure on behavior and executive function in children. Pediatrics. 2011;128(5):873-882. doi:10.1542/peds.2011-1335

4. Kim SE, Kim JD. Middle school girl's awareness and behavior of make-up. J Korean Soc Cosmet Cosmetol. 2019;9(2):211-224.

5. Łopaciuk A, Łoboda M. Global beauty industry trends in the 21 st century. Paper presented at: Management, knowledge and learning international conference; 2013:19-21.

6. Kim H, Lee S. Undergraduate students' perception and satisfaction on convenience food according to food-related lifestyle. Korea Hosp Tour Acad. 2016;25(7):85-96.

7. Wu DY, Tan CB. Changing Chinese Foodways in Asia. Chinese University Press; 2001.

8. Hussein Shehadeh J, Hamdan-Mansour AM. Prevalence and association of premenstrual syndrome and premenstrual dysphoric disorder with academic performance among female university students. Perspect Psychiatr Care. 2018;54(2):176-184. doi:10.1111/ppc.12219

9. Chang HY, Park S. Effects of exposure to endocrine disruptors, burnout, and social support from peers on premenstrual syndrome in nurses. Korean $J$ Women Health Nurs. 2020;26(3):250. doi:10.4069/kjwhn.2020.09.22

10. Nicolopoulou-Stamati P, Hens L, Sasco AJ. Cosmetics as endocrine disruptors: are they a health risk?. Rev Endocr Metab Disord. 2015;16 (4):373-383. doi:10.1007/s11154-016-9329-4

11. Ritchie H, Roser M. Plastic pollution. Our World in Data; 2018. Available from: https://ourwordindata.org. Accessed January 24, 2022.

12. Parashar N, Hait S. Plastics in the time of COVID-19 pandemic: protector or polluter? Sci Total Environ. 2021;759:144274. doi:10.1016/j. scitotenv.2020.144274

13. Schiattarella A, Colacurci N, Morlando M, et al. Plasma and urinary levels of lead and cadmium in patients with endometriosis. Ital J Gynaecol Obstet. 2018;30:21-27.

14. De Franciscis P, Guadagno M, Miraglia N, et al. Follicular PB levels in women attending in vitro fertilization: role of endometriosis on the outcome. Ital J Gynaecol Obstet. 2018;30:21-27.

15. Choi D. The diagnosis and management of premenstrual syndrome, premenstrual dysphoric disorder. Korean Soc Obstet Gynecol Sci. 2019;41:135-146.

16. Victor FF, Souza AI, Barreiros CDT, Barros JLN, Silva FACD, Ferreira ALCG. Quality of Life among university students with premenstrual syndrome. Rev Bras Ginecol Obstet. 2019;41(5):312-317. doi:10.1055/s-0039-1688709

17. Hui K, Ip, S, Leung, H, et al. Premenstrual symptoms among Chinese female undergraduates: relationship with stress and mental health. Hong Kong J Gynaecol Obstet Midwif. 2015;5:10-21.

18. Lenz ER, Pugh LC, Milligan RA, Gift A, Suppe F. The middle-range theory of unpleasant symptoms: an update. Adv Nurs Sci. 1997;19(3):14-27. doi:10.1097/00012272-199703000-00003

19. Kim MR, Kim HC. Recognition, information acquisition behavior, knowledge, behaviors to decrease exposure and education need toward endocrine disruptors among middle and high school students. J Korean Home Econ Educ Assoc. 2009;21(3):123-142.

20. Chung C, Park J, Song JE, Park S. Determinants of protective behaviors against endocrine disruptors in young Korean women. Asian Nurs Res. 2020;14(3):165-172. doi:10.1016/j.anr.2020.07.002

21. Chon KK, Kim KH, Yi JS. Development of the revised life stress scale for college students. Korean J Psychol Health. 2000;5(2):316-335.

22. Allen S, McBride C, Pirie P. The shortened premenstrual assessment form. J Reprod Med. 1991;36(11):769-772.

23. Lee MH, Kim JW, Lee JH, Kim DM. The standardization of the shortened premenstrual assessment form and applicability on the internet. $J$ Korean Neuropsychiatric Assoc. 2002;41(1):159-167.

24. Deshpande S, Basil MD, Basil DZ. Factors influencing healthy eating habits among college students: an application of the health belief model. Health Mark Q. 2009;26(2):145-164. doi:10.1080/07359680802619834

25. Park S, Chung C. Effects of a dietary modification intervention on menstrual pain and urinary BPA levels: a single group clinical trial. $B M C$ Women's Health. 2021;21(1):1-9. doi:10.1186/s12905-021-01199-3

26. Min J, Cha H. The effect of fear and social norm on unmarried woman's intention of visiting gynecology hospital-application of extended theory of planned behavior and interpersonal communication. Korean J Journalism Commun Stud. 2017;61(1):217-250.

27. van der Meer TP, Thio CHL, van Faassen M, et al. Endocrine disrupting chemicals during diet-induced weight loss - A post-hoc analysis of the LOWER study. Environ Res. 2021;192:110262. doi:10.1016/j.envres.2020.110262 
28. Polsky C, Schwarzman M. The hidden success of a conspicuous law: proposition 65 and the reduction of toxic chemical exposures. Ecol Law $Q$. 2020;47:823.

29. Yun SH. Study on Chinese policies and legislation on environmental hormones. Chin Law Rev. 2018;36:609-634. doi:10.22415/clr.2018.36.022

30. Cho T, Lee H. Current status and tasks of endocrine disruptor management in Korea: regulation of bisphenol A, phthalate and nonylphenol. $J$ Law Polit Res. 2018;18(2):73-107. doi:10.17926/kaolp.2018.18.2.73

31. Kim YH, Joung MS, Lee J. Study on health promoting behavior determinant of nursing students. J Korean Public Health Nurs. 2002;16 (2):285-303.

32. Lustyk MKB, Gerrish WG, Douglas H, Bowen S, Marlatt GA. Relationships among premenstrual symptom reports, menstrual attitudes, and mindfulness. Mindfulness. 2011;2(1):37-48. doi:10.1007/s12671-011-0041-x

33. Choi J. The relationship between premenstrual syndrome and depression of female college students in Korea. Indian J Sci Technol. 2016;9(1):1-8.

34. Lee J, Kim SM, Kang SH, et al. Association of premenstrual syndrome and premenstrual dysphoric disorder with depression, sleep quality and sleep pattern in the Korean female high-school students. Anxiety Mood. 2016;12(2):113-118.

35. Kim SK, Kim J, Kim H, An S, Lim Y, Park H. Association between food-related media program watching and dietary behaviors in Korean adolescents. Korean Public Health Res. 2020;46(3):31-46.

36. Liu Q, Wang Y, Van Heck CH, Qiao W. Stress reactivity and emotion in premenstrual syndrome. Neuropsychiatr Dis Treat. 2017;13:1597. doi:10.2147/NDT.S132001

37. So KY, Joe SH, Kim JW, Lee HS, Ko SD. Vulnerability to minor stressful events in young women with premenstrual syndrome. $J$ Korean Neuropsychiatric Assoc. 2002;41(6):1109-1119.

38. Khaled K, Tsofliou F, Hundley V, Helmreich R, Almilaji O. Perceived stress and diet quality in women of reproductive age: a systematic review and meta-analysis. Nutr J. 2020;19(1):1-15. doi:10.1186/s12937-020-00609-w

39. Thys-Jacobs S, McMahon D, Bilezikian JP. Cyclical changes in calcium metabolism across the menstrual cycle in women with premenstrual dysphoric disorder. J Clin Endocrinol Metab. 2007;92(8):2952-2959. doi:10.1210/jc.2006-2726

40. Eissa M. Personality and psychosocial factors affecting premenstrual syndrome. Curr Psychiatr. 2010;17(1):55-62.

41. Hardy C, Hardie J. Exploring premenstrual dysphoric disorder (PMDD) in the work context: a qualitative study. J Psychosom Obstet Gynaecol. 2017;38(4):292-300. doi:10.1080/0167482X.2017.1286473

42. Masho SW, Adera T, South-Paul J. Obesity as a risk factor for premenstrual syndrome. J Psychosom Obstet Gynaecol. 2005;26(1):33-39. doi:10.1080/01443610400023049

International Journal of Women's Health

Dovepress

Publish your work in this journal

The International Journal of Women's Health is an international, peer-reviewed open-access journal publishing original research, reports, editorials, reviews and commentaries on all aspects of women's healthcare including gynecology, obstetrics, and breast cancer. The manuscript management system is completely online and includes a very quick and fair peer-review system, which is all easy to use. Visit http://www. dovepress.com/testimonials.php to read real quotes from published authors.

Submit your manuscript here: https://www.dovepress.com/international-journal-of-womens-health-journal 